\title{
A Study on Approaches to Enhancing the Effectiveness of Social Media Marketing Interaction
}

\author{
Yiru Wang ${ }^{a}$ \\ School of Geoscience and Info-physics, Central South University, Changsha 410012, China \\ awang_yi_ru_@126.com
}

Keywords: marketing, social marketing, interactivity.

\begin{abstract}
With the development of the Internet, social media has become the main platform for public to share information and exchange ideas. For enterprises, using social media marketing can improve marketing effects under the premise of reducing costs. It can also enhance their fame and reputation. Hence, more and more enterprises and brands choose to use social media for marketing activities. Interaction with customers is a significant indicator of marketing effectiveness. The thesis summarizes the relevant models of social media marketing by combing relevant literature, such as the model of effective social marketing through the combination of creation, recommendation, interaction and feedback; or the model of social media marketing based on AIDMA, AISAS model: Attention, Interest, Search, Relationship, Action and Share. Via the combing of model, this thesis proposes the elements that influence social media marketing interaction, namely interactive content, interactive platform, interactive agenda setting, interactive method, and interactive feedback. Based on this and combined with the real cases of social media marketing like Baidu, the thesis puts forward effective ways to improve social media marketing interactivity: 1. Topicality, innovation and entertainment of topic setting; 2. Information highly transparency and authenticity; 3 . The communication ability of the platform, and the connectivity of information delivery; 4 . The stable and long-term relationship establishment; 5. The marketing diversity; 6 . The timely feedback of information. It is advisable to enhance the effectiveness of interaction and boost brand's long-term value from these perspectives.
\end{abstract}

\section{Background Introduction}

With the development of the Internet from era 1.0 to era 3.0, social media has flourished; as a consequence, a series of social media such as Facebook, Wikipedia, Sina Weibo and Wechat came into being as the times required. Social media is widely used by users due to its characteristics of participation, openness, communication, conversation, community and connectivity. It is pointed out in the 2017 China Internet Economy White Book that the total number of Internet users in China is 710 million1. Large user groups, lower marketing costs, and mesh information diffusion enable social media to become an efficient medium for enterprises' marketing publicity and brand transmission.

Social marketing transforms traditional one-way communication transmission into two-way interaction. Customers no longer receive information passively. Moreover, they distribute and disseminate information. For enterprises, social marketing makes it possible for them to contact and integrate into consumers. Via tracking consumer behaviors and demands, enterprises can obtain information more quickly, thus carrying out accurate marketing. In the process of exchanging information with customers, enterprises can obtain first-hand feedback. Consequently, they are able to find their own problems and take relevant measures in time. Meanwhile, it provides the basis and help for the formulation of marketing strategies.

As mentioned in Fang Bing's Brand Content Dissemination based on Social Media Marketing, more than $90 \%$ enterprises in China have picked up the use of social media and are continuously raising the budget of it 2 . It can be seen that social marketing has already become the mainstream way for companies to carry out marketing activities. Nevertheless, how to achieve favorable interaction with customers and achieve a close relationship with them, so as to enhance the impact of corporate brand has become a concern of many enterprises. From the perspective of the features and elements 
of social media, the thesis aims to find out effective ways to enhance interactive effectiveness of corporate social media marketing, by analyzing Baidu Nuomi and other related cases.

\section{Literature Review}

The thesis reviews the relevant theories and literature from three aspects of social media, social media marketing an interactivity, which lays a solid theoretical foundation for the research on how to enhance the effectiveness of social marketing interaction.

\subsection{Definition of Social Media}

Social media was first proposed as a general term of online media by Antony Mayfield in What is Social Media. It gives each person the ability to create and disseminate. The basic characteristics of it are participation, openness, communication, conversation, communication and connectivity. The basic forms are blog, Wikipedia, podcast, forum, social network, and content community, etc3. The concept defines social media from all aspects, namely from the realization of social media, basic characteristics and classification. With the development of the society, the concept of social media has been simplified. For instance, "social media is the media platform based on the Internet, which gives users lots of space for participation and communication". "Social media is a new type of online media that provides users with a great deal of space to participate in, with the characteristics of authenticity, participation, and community". Although there are many different definitions, social media originated from Internet technology, of which the core is interaction. These two aspects are the root of all definition.

For the concept of social media, the thesis recognizes the point of view put forward in the Origin and Development of Social Media Concept by Tian Li and Hu Xuan. Based on interaction, social media is a form of Internet social organization that allows individuals and organizations to create and exchange production content. In addition, it attaches to and is able to establish, expand and consolidate relationship network4. The concept meets the circumstances of social media in China. Meanwhile, it clearly puts forward the core, content source, and structure of social media. It also describes social media's characteristics of high involvement and interactivity, which is of benefit for the extraction of key elements of social marketing in this thesis.

\subsection{Classification of Social Media}

The classification of social media in academic circle is relatively unified. Partly, social media is divided by purpose into social relationship, video sharing, photo sharing, collaborative terms, news sharing and content selection. The other part is classified by the application of social media: blog, wikis, podcast, forums, social networks, content communities and micro blog.

In this thesis, we do not focus on certain social media as the marketing media for research. Instead, it is discussed in a general sense. Hence, the social media studied covers the above categories.

\subsection{Definition of Social Media Marketing}

Social media marketing, literally, is a method of using social media for marketing, with social media as the communication media and marketing as the ultimate goal. Fu Hong'an pointed out in the Study on Application of Big Data in Social Media Marketing: on the basis of traditional Internet marketing, social media marketing emphasizes participation and interaction. The key point of it is to cultivate users' habits via the interaction with them, and to design and provide personalized products and services based on their needs5. From the perspective of word-of-mouth marketing, social media marketing is the innovative marketing which takes advantage of the nature of media itself.

Compared with traditional marketing methods, social media marketing is a change from the method of notification to communication. The users change from receiving passively to publishing actively. From the aspect of transmission way, it changes from one-way to two-way, and even multiple ways. In the field of transmission path, it changes from single path to a mesh diffusion one. As for the persistence of its transmission influence, traditional marketing method has a short duration, and the influence of it will be gradually reduced; while the transmission influence of social media marketing grows with the increase of duration. Therefore, social media marketing is the dynamic marketing that covers the whole process from $\mathrm{P}$ to $\mathrm{R}$ then to $\mathrm{C}$. 


\subsection{Features of Social Media}

\subsubsection{High Interactivity}

Interactivity has always been an element and criterion for evaluating the effectiveness of marketing; however, in social media marketing, interactivity is the foundation and core. Enterprises ought to build nice interaction. Only in this way can they enter the stage of relationship maintenance. At the same time, it makes the users enjoy a strong sense of trust and recognition of the brand. And they voluntarily become the disseminator of corporate reputation, building brand fans groups. High interactivity is not only reflected between enterprises and users, but also between the user and user. Compared to traditional one-way marketing, social media marketing enables users to become friends. Meanwhile, the relationship between enterprises and clients is no longer seller and buyer, but equal relationship.

\subsubsection{The User is Also the Media}

In social media marketing, customers no longer receive single message passively, but also create and disseminate information. Customers can spread a certain shopping experience or evaluate a certain brand through social media. Besides, other users in this social media platform can also become the transmitter of the message, so that they can play the role of media. Meanwhile, since users of platform may be friends or relatives, communication among such strong relationship is even more convinced than by media.

\subsubsection{High Stickiness of Customer Relationship}

Traditional marketing widely relies on advertisement for promotion. Therefore, there is basically no interaction and relationship with customers. Customers are passive receivers. However, due to its strong interactivity, social media marketing will establish initial relationships with customers in the process of interaction. With the increase of interaction and time going by, customers will be more aware of enterprises. There will also be a strong connection and high stickiness. Such high stickiness will make customers become the advisers of enterprise product innovation, the planners of marketing, and the propagandists for brand. On the one hand, enterprises are able to make innovations better. On the other hand, it also makes customers become one part of the brand, which means that they have a sense of belonging for the brand, thus forming the partner relationship and increasing brand loyalty.

\subsubsection{Fragmented Propagation}

Fragmented propagation refers to the refusal of using "big trumpet" to disseminate information widely; however, it offers related information to a certain group or individuals. Traditional way of dissemination is to increase coverage and the credibility through the major media and events. Whereas social media marketing caters for different groups and their characteristics, influencing customers by their sense of value and belonging. Similar to MiTal, such marketing is favourable to establish a customer circle with corporate characteristics.

\subsubsection{Soft Transmission}

In traditional marketing, enterprises directly deliver information to customers in a preaching style via images, texts, videos, etc. While in social media marketing, enterprises are supposed to lower down their stance and become listeners, observers as well as communicators. They should improve their own products by listening to the needs and feedback of clients. They should create and guide consumer behavior by observation and analysis. They should reflect the client-oriented selling concept by communication and equal conversation, reducing the customer dissatisfaction bought by "interfering marketing".

\subsubsection{Accurate Description of Consumer Behaviors}

In the information era of highly-developed Internet and technologies, consumer behaviors can be recorded when making relevant purchase decisions. Enterprises can make more accurate description of consumer purchase behavior, according to their relevant behavior or remarks in social media platform and consumer purchase decision. Combined with related big data analysis technologies, the accurate marketing and service are provided to consumers.

\subsubsection{High Publicity}

In traditional marketing, corporate information, customer information and communication between companies and clients are relatively secretive. However, in social media marketing, 
enterprises are almost completely exposed to the media, information being highly public. For customers, some related personal information or records are also entirely open to enterprises.

\subsubsection{Low Cost}

Compared to traditional advertising-target marketing, the cost of social media marketing is relatively low. Moreover, the innovation of content or topics counts. Meanwhile, because of fast speed and wide range of transmission and no geographical restriction, it consists of the characteristics of low-cost investment and high-efficiency recovery.

\subsubsection{Real Time}

Compared with traditional marketing's characteristics of fixed time and regular space, social media breaks the boundary of time and space. As long as the Internet is available, enterprises can lead to real-time interaction and dissemination, anytime and anywhere.

\subsection{Elements of Social Media Marketing}

By combing the literature, the thesis finds out that scholars have classified the elements involved in social media marketing from different aspects. Some of them classify them by various subjects that participate in social media marketing: enterprises, social media, social media marketing strategies, audiences, social media users, customers; there are elements division based on $4 \mathrm{P}$ or $4 \mathrm{C}$; there are also elements extraction from the perspective of communication: content, dissemination contact point, opinion leaders; agenda setting, effect feedback; many scholars have combed the elements from marketing effect, namely communication power, conversation power, capability of value transition, and long-term brand influence. In a word, for the elements involved in social media marketing, starting from different classification criteria may generate different classification criteria.

The thesis mainly focuses on the specific issue of social media marketing interactivity. Thus the combination of social media marketing elements and interactivity is divided into the following five elements: interactive content, interactive platform, interactive agenda setting, interactive method, and interactive feedback. The thesis will discuss in detail based on these five elements.

\subsection{Social Media Marketing Model}

In Study on Social Media Marketing Innovation Model, Xue Wenwen created PCCP social media marketing innovation model6. P refers to product. This product not only refers to tangible products and intangible service provided by enterprises, but also refers to the integration of corporate image and product. $\mathrm{C}$ means customer. In the field of social media marketing, customer contains the traditional sense of customer. What's more, it concludes the source of information, objects of acceptance and feedback. C means communication, which is the interaction between enterprises and customers. The last one P refers to place, that is, the integration of online and offline channels. The concrete model is shown in Figure 1. This model makes innovation on the basis of traditional traditional marketing, integrating the characteristics of social media.

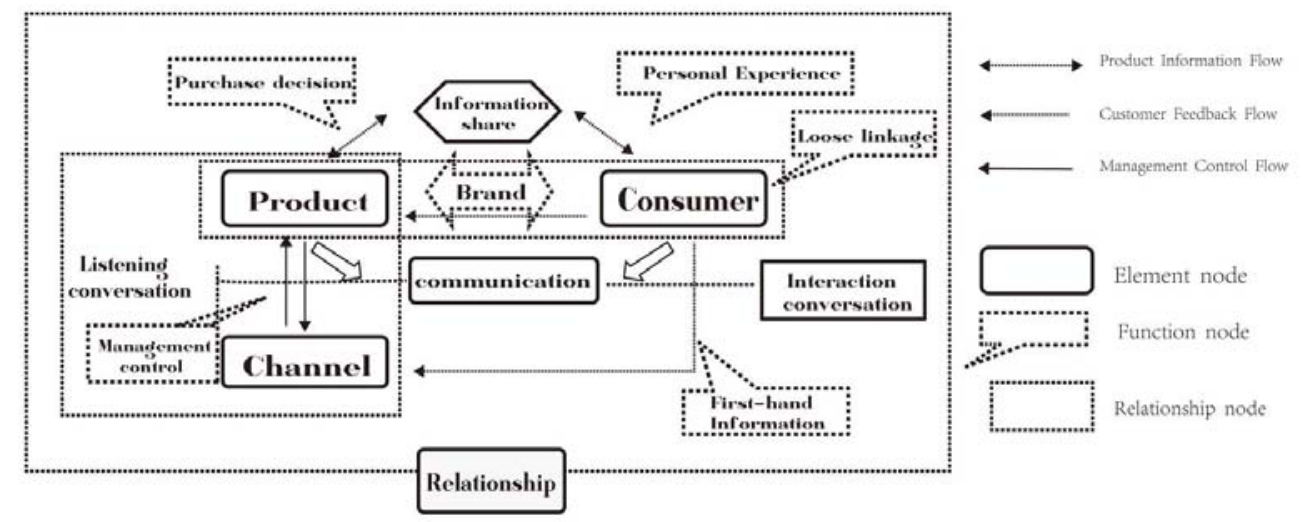

Figure.1 Social Media Marketing Model: PCCP

Liu Xiaowei proposed social media marketing based on AISRAS in Study on Social Media Marketing, namely Attention, Interest, Search, Relationship, Action, and Share. The establishment of the model is mainly based on the interaction feedback between enterprises and users. 


\section{Research Perspective}

The thesis aims to improve the interactive effectiveness. Via the extraction of interactive elements in social media marketing: interactive content, interactive platform, interactive agenda setting, interactive method, interactive feedback, it proposes an effective way to improve the effectiveness of interaction and the long-term value of the brands: topicality, innovation, and entertainment of the content setting; information transparency and authenticity; the communication capabilities of the interactive platform, connectivity of information communication; the stability and longevity of the relationships; diversity of marketing modes; timeliness of feedback.

\section{Problems in Enterprise Social Media Marketing}

The thesis studies social media marketing of Mi, Baidu Nuomi and some small and medium-sized enterprises. In this study, it is founded out that the interactive effect of Internet or information science, or E-commerce based enterprises is much more effective than non-network information based companies; partly because that technology has a powerful effect on social media marketing recommendation. For instance, big data analysis plays a significant role in consumer behavior, consumer decision and accurate marketing, making marketing more personalized. On the other hand, companies own business and operational characteristics may influence the effect of social media marketing.

The thesis summaries the problems of social media marketing in terms of interactivity. 1 . The content of interactive topics is not story-like, which means that it has a strong brand output, making users unsympathetic. In social media marketing, the setting of interactive topic is to attract users' interest and attention, so that they can share or spread information spontaneously. 2. The use of interactive platform and social media cannot satisfy the needs of pertinence. When enterprises carry out social media marketing campaigns, they might publish the same content on multiple platforms. Similar to traditional advertisement-covered marketing, such means of promotion can only play the role of publicity. Additionally, it is a misunderstanding of social media. Social media marketing outshines others because of its own characteristics and user groups. Consequently, non-emphasis and blind use of social media can hardly improve the interactive effect. 3 . There is a lack of continuity of interactive setting, when it comes to the setting of interactive topic and the entire interactive agenda. The lack of continuity may result in the effect of communication in the short run; however, it may easily lead to the users' instant interest. In other words, they may no longer carry out continuous, indepth attention, which is an obstacle for enterprises to achieve the establishment of corporate loyal users or fans groups. 4. The simplification of dissemination methods. Due to the low cost of social media, many enterprises largely use this method. Nevertheless, through the promotion case of Mi and Baidu Nuomi, only using a single social media marketing is difficult to form a large-scale and longterm effect. It is also hard to make users or customers have a deeper understanding of the brands or services. 5. The timeliness of handling customer's message. Writer Liuliu once complained of JD.com, for it did not respond to customers' complaint, not mentioning solving the complaints. This illustrates that in the era of information, the sharing of information has become increasingly significant, which also adds to the transparency of information. As a result, never can enterprises pay too much attention to the complaints and suggestions of users. Meanwhile, it is essential to respond to the continuous information source or information receivers, which shows the respect for users. The feeling of being appreciated will inspire users to share and pass positive information.

Social media marketing is a kind of new-emerging marketing. The scarcity of talented persons also affects the interactive effect. The blind pursuit of social media marketing and the ambiguity of marketing goals make it tough for enterprises to accurately provide relevant steps and plans, thus largely affecting the effectiveness of marketing. 


\section{Suggestion on Enhancing Social Media Marketing Effectiveness}

The thesis summarizes the methods and experiences of successful cases in social media marketing. First and foremost, the choice of interactive topics should be able to attract users' interest. It is necessary to conduct research and analysis on the consumer habit of target user groups, and to choose topics that can arouse consumers' interest or sympathy. The topic can be innovative, entertaining and story-like, thus making it integrated into consumers' daily life. Meanwhile, it can convey the characteristics or values of the products or enterprise itself. The microblog of $\mathrm{Mi}$ has the characteristics of youngsters' pursuit of entertainment and fashion. The constellation, romance, jokes, anecdotes are treated as topics to arouse discussion or interaction; while that of Huangtaiji's pancake tightly captures the independence of youngsters. It uses the topics that highlight personality and strengthen their own characteristics, such as thinking deeply of life when eating pancakes and drinking tofu jelly. We might as well create topics according to current events and closely follow the characteristics and needs of target user groups, making topics become the contact point of users with brands and adding to their attention.

Secondly, when it comes to the selection of interactive platform, there must be some certain targeted and focused media choices. Each user group of media has its own audiences and characteristics. Their authority, entertainment, and profession are not exactly the same. Therefore, in the selection of social media, it is essential to focus on the selection and development and consider marketing goals and platform characteristics. Thirdly, in terms of the setting of interactive agenda, attention should be paid to finding opinion leaders that have a certain influence in the discussion of the topic, so that opinion leaders can lead to deeper and more widespread communication. Meanwhile, it is advisable to give one-stop marketing strategy support, which enables information or topics to be continuously created and updated. For instance, experience marketing and other ways can make interaction deep and lasting.

In the interactive way, importance should be attached to the cooperation of online and offline marketing methods. Traditional marketing should be combined with social media marketing. Traditional marketing can achieve wide publicity effect at the fastest speed, whereas social media marketing can solve in-depth problems. The combination of them is of benefit for establishing consumer loyalty. The feedback of interactive information is a significant element that enterprises must pay attention to in the era of information. Some improvement can add to the consumer acceptance of the brand, such as the openness of the brand, the transparency and authenticity of information. Meanwhile, users' opinions and suggestions should be responded to promptly, which serves as the reflection of the partner relationship and the relationship of equal conversation, rather than the relationship between buyers and sellers. Such positive and timely response to information can turn something bad into something good. It is an effective way for enterprises to shoulder social responsibilities. Besides, this kind of information collection and processing enables enterprises to better understand users' needs, thus upgrading the existing products or marketing methods for enterprise' preferable development. Via the continuous information generation and feedback, enterprises establish contacts between users, and the relationship turns from weak to strong.

The promotion of interactive effects in social media marketing is not the result of a single factor, but integrated marketing of multiple factors. The promotion of interactive effect is indeed the process in which the relationship between enterprises and customers turns from weak to strong. The core of it is users' need. Hence, the mining, tracing and guiding of users' needs are also indispensable sessions. Through the establishment of social media marketing and business chain of innovative enterprises, a one-stop marketing platform makes it possible for enterprises and customers to form a close partnership. Focusing on the user and listening to their suggestions and needs enable users to take part in the establishment and development of enterprises or brands, making them become the masters of the brand and effectively stimulating the conscious sharing behaviors. Such kind of sharing has a positive effect on the reality transition of marketing value and the promotion of brand's longterm value. 


\section{Conclusion}

By the means of literary review, the thesis innovatively puts forward the interactive elements in social media marketing: interactive content, interactive platform, interactive agenda setting, and interactive feedback. Through real experiences, it summarizes the problems in corporate social media marketing. It proposes the methods to enhance interactive effectiveness: 1 . The setting of interactive topics should be topical, innovative, and entertaining; 2 . Increase the transparency and truthfulness of corporate information, and raise awareness of responsibilities; 3 . The communication capabilities of interactive platforms ensure the high connectivity of information transition; 4. Establish a stable, long-term and equal relationship with users; 5. Focus on the diversity of marketing methods; 6 . Handle user messages and information feedback promptly.

Since each enterprise has its own uniqueness in terms of product, operation, etc. User groups and marketing goals are different as well. Consequently, it is of limitation for the thesis to separately describe it. When carrying out social media marketing, enterprises ought to consider their own circumstances and flexibly use different elements and methods, with concrete focus and aims.

\section{References}

[1]. 2017 China Internet Economy White Book.

[2]. Fang Bing. Brand Content Dissemination Based on Social Media Marketing.[D]

[3]. Antony Mayfield. What is Social Media. [D]

[4]. Tian Li, Hu Xuan.the Origin and Development of Social Media Concept. [D]

[5]. Fu Hong an. Study on Application of Big Data in Social Media Marketing. [D]

[6]. Xue Wenwen. Study on Social Media Marketing Innovation Model. [D]

[7]. Liu Xiaowei .tudy on Social Media Marketing. [D] 